\title{
Tempo de trabalho e de ensino: composição da jornada de trabalho dos professores paulistas ${ }^{1}$
}

\author{
Andreza Barbosa ${ }^{2}$ \\ ORCID: 0000-0003-0363-7608 \\ Maria José da Silva Fernandes ${ }^{3}$ \\ ORCID: 0000-0002-4747-6570 \\ Renata Cristina Oliveira Barrichelo Cunha ${ }^{4}$ \\ ORCID: 0000-0002-5662-8062 \\ Thiago Borges de Aguiar ${ }^{5}$ \\ ORCID: 0000-0002-7294-1200
}

\section{Resumo}

Tendo em vista a dificuldade de se quantificar o tempo efetivamente trabalhado pelos professores, posto que os dados oficiais disponibilizados frequentemente consideram somente o tempo passado em sala de aula, ou o tempo contratual, este texto apresenta resultados de uma pesquisa que analisou a constituição da jornada de trabalho dos professores da rede pública estadual paulista. Buscou-se investigar e problematizar a constituição da jornada de trabalho dos professores dos anos finais do ensino fundamental e ensino médio dessa rede, considerando o tempo em sala de aula e o tempo destinado ao trabalho extraclasse. A pesquisa em questão foi realizada em um município do interior paulista em duas etapas: na primeira, aplicaram-se questionários com professores de trinta escolas. Na segunda, realizou-se um aprofundamento qualitativo dos dados levantados na primeira etapa por meio da realização de entrevistas semiestruturadas com um grupo de treze professores. Os resultados obtidos evidenciam que o tempo de trabalho dos professores é bastante superior ao tempo oficial que sua jornada de trabalho compreende, o que significa que grande parte do tempo destinado ao trabalho extraclasse não é remunerado, embora sirva para a realização de atividades essenciais para atuação dos professores junto aos alunos. Destacou-se, ainda, que os professores que participaram da pesquisa têm ampliado suas jornadas de trabalho para compensar os baixos salários recebidos, o que se soma ainda ao aumento da demanda de trabalho e à desvalorização docente, conforme relatado pelos professores.

\footnotetext{
1- Este trabalho traz dados de pesquisa desenvolvida com apoio do Fundo de Apoio à Pesquisa da Universidade Metodista de Piracicaba.

2- Universidade de Sorocaba, Sorocaba, SP, Brasil. Contato: andrezab27@gmail.com

3- Universidade Estadual Paulista "Júlio de Mesquita Filho", Bauru, SP, Brasil. Contato: mj.fernandes@unesp.br

4- Instituto Pecege, Piracicaba, SP, Brasil. Contato: renata_bcunha@yahoo.com.br

5- Universidade de São Paulo, São Paulo, SP, Brasil. Contato: tbaguiar@outlook.com.br
} 


\title{
Palavras-chave
}

Condições de trabalho docente - Jornada de trabalho docente - Tempo de trabalho Trabalho extraclasse - Rede pública de ensino paulista.

\section{Working time and teaching time: composition of the working hours of São Paulo teachers}

\begin{abstract}
Given the difficulty of quantifying how much time teachers actually work, since the official data available often only consider the time spent in the classroom, or the contractual working hours, this paper presents results of a research that analyzed the constitution of the working hours of teachers in the public school system in the state of São Paulo. We investigated and problematized the constitution of the working hours of teachers in the final years of elementary and secondary education in the mentioned school network, considering classroom time and extra-class work time. The research in question was carried out in a city in the countryside of São Paulo in two stages: in the first, questionnaires were applied to teachers from thirty schools. In the second, an in-depth qualitative analysis of the data collected in the first stage was conducted through semi-structured interviews with a group of thirteen teachers. The results obtained show that the working time of teachers is much longer than the official time that their working day consists of, which means that a great deal of the time devoted to extra-class work is unpaid, although it serves to perform essential activities for teachers to work with students. It was also highlighted that the teachers who participated in the survey have expanded their working hours to compensate for the low salaries received, which is also added to the increased work demand and the devaluation of teachers, as reported by them.
\end{abstract}

\section{Keywords}

Teaching work conditions - Teaching work hours - Working time - Extracurricular work

- São Paulo public education system. 


\section{Introdução}

0 baixo desempenho dos estudantes brasileiros nas avaliações em larga escala costuma ocupar lugar de destaque no discurso oficial e na mídia em geral. No esteio da divulgação de dados observamos uma série de proposições que buscam apresentar soluções para a melhoria dos resultados educacionais no país, tais como padronização curricular na educação básica, mudanças nos métodos de ensino, alterações no currículo da formação dos professores, implementação de programas de gestão, pagamento por desempenho, controle de resultados etc. As condições de trabalho docente, entretanto, dificilmente são apontadas como fundamentais para a melhoria da qualidade da educação, salvo por pesquisas realizadas no campo da educação (GOUVEIA et al., 2006; BARBOSA, 2011; RODRIGUES, 2018).

As condições de trabalho docente referem-se, por um lado, aos recursos necessários para o desenvolvimento das atividades laborais, como instalações físicas, materiais pedagógicos, insumos e equipamentos necessários para ensinar e, por outro, às relações a que o professor está sujeito em seu local de trabalho, como constrangimentos e pressões (ASSUNÇÃO, 2011). De acordo com Oliveira e Assunção (2010, p. 1), as condições de trabalho não se restringem ao conjunto de meios necessários à realização de uma atividade, mas contemplam relações específicas que "[...] dizem respeito ao processo de trabalho e às condições de emprego (formas de contratação, remuneração, carreira e estabilidade)". Assim, são condições e relações sine qua non para a melhoria dos processos de ensino e aprendizagem. Porém, definir o que são condições adequadas para realização do trabalho docente não é tarefa fácil numa profissão com tantas diferenças internas (FERNÁNDEZ ENGUITA, 1991).

A jornada docente, elemento que compõe as condições de trabalho, é difícil de ser aferida, pois não é definida exclusivamente pelo tempo marcado do relógio e pelas atividades circunscritas à escola. Segundo Souza (2008), o trabalho docente envolve o tempo de ensino efetivamente cumprido em sala de aula e o tempo extraclasse despendido em outros espaços, com tarefas intrínsecas à realização da docência, como preparação de aulas, elaboração e correção de atividades de ensino e de avaliação. A jornada de trabalho extraclasse, que muitas vezes ultrapassa os limites do tempo contratual docente, não pode ser considerada trivial, já que é constituinte e fundamental para o bom exercício da profissão. A realização da aula ou a aplicação de uma prova sem elaboração prévia acarreta prejuízos à organização do processo pedagógico e, consequentemente, à qualidade do ensino e aprendizagem.

Dada a importância da jornada, apresentamos neste artigo resultados de uma pesquisa realizada entre 2014 e $2018^{6}$, cujo objetivo central foi: investigar e problematizar a constituição da jornada de trabalho dos professores dos anos finais do ensino fundamental e ensino médio da rede pública estadual paulista, considerando o tempo em sala de aula e o tempo destinado ao trabalho extraclasse. A primeira etapa da pesquisa foi composta pela coleta de informações via questionário fechado aplicado aos professores de escolas localizadas em um municipio de porte médio do interior paulista. A opção pelas

6- A pesquisa foi aprovada pelo Comitê de Ética da instituição responsável (Protocolo CEP nº 06/2014 e nº 141/2015). 
etapas finais da educação básica deu-se pela maior complexidade do trabalho realizado por professores que atuam em diferentes disciplinas do currículo e variadas turmas, com elevado número total de alunos atendidos durante a semana, além de serem etapas com maiores índices de absentismo e rotatividade docente (PAGANI, 2019). Das 42 escolas do município que atendiam a essas etapas de escolaridade em 2014, período da coleta, trinta aceitaram participar da pesquisa. 0 número total de docentes era aproximadamente 1.800 e, desses, 464 (25,7 por cento) responderam ao questionário que abordava a caracterização dos sujeitos, situação funcional, formação e composição da jornada de trabalho. Os dados obtidos foram tabulados e analisados em 2015 à luz do referencial teórico, o que permitiu uma compreensão ampla da composição da jornada de trabalho docente desses professores.

Na segunda etapa da pesquisa, realizada entre 2016 e 2018, buscamos a compreensão qualitativa da jornada de trabalho docente por meio da realização de entrevistas semiestruturadas. Foram convidados todos os professores das três escolas do município nas quais o número de respondentes na primeira etapa da investigação foi proporcionalmente maior em relação à quantidade total de docentes na instituição. As escolas somavam 129 docentes, dentre os quais treze foram entrevistados. As entrevistas aconteceram no segundo semestre de 2016 e primeiro semestre de 2017, foram audiogravadas e realizadas a partir de roteiro previamente elaborado, em local e horário escolhidos pelos professores, sendo posteriormente transcritas e analisadas.

Embora circunscritos aos professores da rede pública estadual paulista que atuavam em um município específico do interior de São Paulo, os resultados dessa pesquisa reafirmaram a complexidade da jornada de trabalho, aspecto normalmente desconsiderado nos levantamentos que embasam a formulação e proposição de políticas públicas para a educação, especialmente aquelas que visam ampliar os resultados de desempenho dos alunos nas avaliações externas, compreendidas, muitas vezes, como sinônimo de qualidade.

Este texto está organizado de forma a discutir, inicialmente, a especificidade da jornada de trabalho docente, evidenciando os elementos que a diferenciam da jornada de outros trabalhadores. Posteriormente, apresenta-se a análise dos resultados da pesquisa mencionada, destacando os obtidos na primeira etapa, na qual foram coletados dados quantitativos, possibilitando uma compreensão ampla da composição da jornada de trabalho docente dos professores paulistas. Serão apresentados também os resultados da segunda parte da investigação que, baseada em dados qualitativos, possibilitou o aprofundamento da compreensão dessa jornada.

\section{Especificidade da jornada de trabalho docente}

Para Duarte (2008), a jornada docente é, por um lado, extensa porque vai além das horas de trabalho cumpridas com os alunos em sala de aula e pode incluir o aumento do número de horas trabalhadas pelos professores, com novas escolas e novas turmas, como forma de compensar os baixos salários recebidos, mas, por outro lado, é intensa porque as demandas que envolvem o cotidiano de trabalho são muitas e exigentes.

Pesquisas realizadas por autores como Gouveia et al. (2006), Barbosa (2011), Oliveira e Vieira (2012), Faria e Rachid (2015), Jacomini, Gil e Castro (2018, 2019), tanto como 
documentos organizados por pesquisadores, institutos ou organismos internacionais (UNESCO, 1966; SINISCALCO, 2003; GATTI; BARRETTO, 2009; IPM, 2010), em diferentes momentos, apontaram para a necessidade de uma composição de jornada que permitisse aos professores dedicação não apenas às atividades em sala de aula, mas também às atividades extraclasse.

Gouveia et al. (2006) sinalizaram que a jornada se relaciona à qualidade da educação de forma complexa, pois ela deve permitir a integração do professor à escola com condições adequadas que considerem a especificidade do trabalho docente:

Além da necessária discussão da jornada de trabalho do professor no conjunto da regulamentação do trabalho em geral, é preciso considerar as especificidades do trabalho do professor e talvez avançar na definição do que são doenças tipicamente profissionais numa profissão em que as relações interpessoais não são secundárias no processo de trabalho. (GOUVEIA et al., 2006, p. 263).

Barbosa, Cunha e Martins (2019), a partir de levantamento do estado do conhecimento acerca da jornada docente, sistematizaram alguns elementos importantes sobre os estudos analisados, destacando que eles apontaram para: a necessidade de se considerar a especificidade do trabalho docente; a vinculação da jornada de trabalho à discussão dos salários dos professores, já que eles costumam ser pagos tendo como referência a jornada de trabalho assumida e, também, em função da ampliação da jornada ser um recurso para compensar os baixos salários; a relação da jornada à questão de gênero, uma vez que entre os docentes a maioria é formada por mulheres, que tendem a acumular o trabalho docente com as tarefas domésticas e os cuidados com os filhos; a vinculação da jornada à regulação feita pelas normas e leis dos sistemas de ensino.

Sobre o último ponto destacado pelas autoras, é importante sinalizar que a legislação brasileira estabelece diretrizes e normas para a organização da jornada de trabalho dos professores. Em 2009, foi publicada a Resolução n 2 do Conselho Nacional de Educação (CNE) e da Câmara de Educação Básica (CEB), que fixou diretrizes para os planos de carreira e remuneração dos profissionais do magistério da educação básica pública, definindo que a jornada de trabalho docente fosse preferencialmente de tempo integral, com duração máxima de 40 horas semanais e recomendação de ampliação de parte da jornada "[...] destinada às atividades de preparação de aulas, avaliação da produção dos alunos, reuniões escolares, contatos com a comunidade e formação continuada [...]" (BRASIL, 2009, p. 2). Embora a referida lei não tenha avançado na fixação de porcentagem mínima destinada ao trabalho extraclasse, reforçou a compreensão de que as atividades realizadas fora do tempo em sala de aula são constituintes da docência e devem integrar as jornadas de trabalho dos professores.

Antes mesmo da aprovação da resolução, a Lei do Piso Salarial Profissional Nacional estabeleceu, além do valor mínimo para remuneração dos professores, que a composição das jornadas de trabalho docente deveria ter no mínimo 1/3 do tempo destinado ao trabalho extraclasse (BRASIL, 2008). Aprovada em 2008, a lei foi alvo de Ação Direta de Inconstitucionalidade (Adin), movida por governadores de cinco estados brasileiros e, em função disso, somente em 2011, após deliberação de constitucionalidade pelo Supremo Tribunal Federal (STF), é que a parte da lei referente à jornada foi colocada em vigor. 
Jacomini, Gil e Castro (2019), ao estudarem o cumprimento da Lei do Piso Salarial Profissional Nacional nos estados brasileiros, constataram que, após oito anos da aprovação dessa lei, somente dez estados cumpriam integralmente a composição da jornada de trabalho docente por ela estabelecida. Ainda segundo esses autores, o estado de São Paulo estaria entre os estados que não atendem à lei no que diz respeito à destinação de $1 / 3$ da jornada ao trabalho extraclasse.

$\mathrm{Na}$ verdade, o estado de São Paulo buscou atender a essa determinação legal em 2012, fazendo um ajuste na composição da jornada de trabalho dos professores que frustrou as expectativas da categoria. Até então, um professor com jornada integral de 40 horas semanais cumpria um total de 33 horas-aula, com duração de 50 minutos, em sala de aula e 7 horas-aula com a mesma duração em atividades extraclasse. A expectativa com a Lei do Piso era que os professores passassem a cumprir 27 horas-aula com alunos e 13 horas-aula ( $1 / 3$ de 40 horas-aula) em atividades de trabalho extraclasse.

Porém, segundo Fernandes e Barbosa (2014), o governo realizou uma manobra contratual para se ajustar à lei, resgatando o texto do Plano de Carreira, Vencimentos e Salários do Quadro do Magistério (SÃO PAULO, 1997), que previa a duração da hora de trabalho em 60 minutos. Assim, foram necessários poucos ajustes e a jornada que antes durava 40 horas-aula (de 50 minutos) passou a ser considerada com a duração de 40 horas relógio, correspondendo a 48 horas-aula, tendo como 1/3 apenas 16 horas-aula.

Ao fazer a subtração desse tempo do total de 48 horas-aula, os professores precisariam cumprir 32 horas-aula em sala de aula, apenas 1 hora-aula a menos que as 33 praticadas anteriormente. A partir de então, com a Resolução SE nº 8, de 19 de janeiro de 2012 (SÃO PAULO, 2012), a jornada de trabalho dos professores paulistas passou a ser organizada da seguinte forma:

Quadro 1 - Organização atual da jornada de trabalho dos professores da rede pública estadual paulista

\begin{tabular}{|c|c|c|c|}
\hline \multirow{3}{*}{ Jornada Integral } & \multirow{3}{*}{$\begin{array}{c}\text { 40h } \\
\text { ou } 48 \text { horas-aula }\end{array}$} & \multicolumn{2}{|c|}{32 h/aula atividades com estudantes } \\
\hline & & \multirow{2}{*}{$\begin{array}{c}16 \text { h/aula trabalho } \\
\text { pedagógico }\end{array}$} & 3 h/aula na escola \\
\hline & & & 13 h/aula local de livre escolha \\
\hline \multirow{3}{*}{ Jornada Básica } & \multirow{3}{*}{ 30h ou 36 horas-aula } & \multicolumn{2}{|c|}{24 h/aula atividades com estudantes } \\
\hline & & \multirow{2}{*}{$\begin{array}{c}12 \text { h/aula trabalho } \\
\text { pedagógico }\end{array}$} & 2 h/aula na escola \\
\hline & & & 10 h/aula local de livre escolha \\
\hline \multirow{3}{*}{ Jornada Inicial } & \multirow{3}{*}{ 24h ou 28 horas-aula } & \multicolumn{2}{|c|}{19 h/aula atividades com estudantes } \\
\hline & & \multirow{2}{*}{9 h/aula trabalho pedagógico } & 2 h/aula na escola \\
\hline & & & $7 \mathrm{~h} /$ aula local de livre escolha \\
\hline \multirow{3}{*}{ Jornada Reduzida } & \multirow{3}{*}{$12 \mathrm{~h}$ ou 14 horas-aula } & \multicolumn{2}{|c|}{9 h/aula atividades com estudantes } \\
\hline & & \multirow{2}{*}{5 h/aula trabalho pedagógico } & 2 h/aula na escola \\
\hline & & & 3 h/aula local de livre escolha \\
\hline
\end{tabular}

Fonte: Elaboração própria, com base na Resolução SE nº 8, de 19 de janeiro de 2012 (SÃO PAULO, 2012). 
Para compreender os significados dessa composição da jornada de trabalho na rede pública estadual paulista, nos aproximamos do cotidiano dos professores, buscando, para além da aparência, identificar o que o número de horas que compunha oficialmente as jornadas ocultava.

\section{Características da jornada de trabalho docente: o que os dados revelaram}

Visando aprofundar o conhecimento sobre a composição da jornada, perguntamos aos 464 professores que participaram da primeira etapa da pesquisa o número de aulas semanais trabalhadas na rede pública paulista e o número de aulas trabalhadas em outras redes, públicas ou privadas. Os professores responderam a essas questões com números absolutos, que foram agrupados em intervalos de dez em dez aulas.

Tabela 1 - Número de aulas dos professores na rede pública estadual paulista

\begin{tabular}{|c|c|c|}
\hline $\mathrm{N}^{0}$ de aulas semanais & $\mathrm{N}^{0}$ de professores & $\%$ \\
\hline $1-10$ & 29 & $6,25 \%$ \\
\hline $10-120$ & 86 & $18,53 \%$ \\
\hline $20-130$ & 162 & $34,91 \%$ \\
\hline $30-140^{*}$ & 151 & $32,54 \%$ \\
\hline $40-150$ & 12 & $2,59 \%$ \\
\hline $50-160$ & 10 & $2,16 \%$ \\
\hline mais que 60 aulas & 1 & $0,22 \%$ \\
\hline Rasurado/Em Branco & 13 & $2,80 \%$ \\
\hline TOTAL & 464 & $100,00 \%$ \\
\hline
\end{tabular}

* 106 declararam ministrar 32 aulas, 0 que representa 22,84\%.

Fonte: Elaboração própria, com base em dados obtidos com o questionário da pesquisa.

Quando observado o número de aulas trabalhadas na rede pública estadual paulista, surpreende a existência de aproximadamente 5 por cento de professores que trabalham mais de 40 horas-aula por semana. A maior incidência de respostas se situa nas faixas de 20-30 e 30-40 horas-aula semanais, que totalizam mais de 67 por cento dos respondentes. No entanto, o número de aulas trabalhadas por esses professores, considerando também outras redes, alterou-se de forma significativa, havendo redução dos estratos inferiores (entre 1 e 30 horas) e um aumento dos estratos superiores (entre 40 e 60 horas), conforme Tabela 2: 
Tabela 2 - Número total de aulas assumidas pelos professores em todas as redes nas quais trabalham

\begin{tabular}{|c|c|c|}
\hline $\mathrm{N}^{0}$ de aulas semanais & $\mathrm{N}^{0}$ de professores & $\%$ \\
\hline $1-10$ & 19 & $4,09 \%$ \\
\hline $10-120$ & 67 & $14,44 \%$ \\
\hline $20-130$ & 126 & $27,16 \%$ \\
\hline $30-10$ & 150 & $32,33 \%$ \\
\hline $40-150$ & 46 & $9,91 \%$ \\
\hline $50-160$ & 38 & $8,19 \%$ \\
\hline mais que 60 aulas & 5 & $1,08 \%$ \\
\hline Rasurado/Em Branco & 13 & $2,80 \%$ \\
\hline TOTAL & 464 & $100,00 \%$ \\
\hline
\end{tabular}

Fonte: Elaboração própria, com base em dados obtidos com o questionário da pesquisa.

$\mathrm{Na}$ Tabela 2, a porcentagem de professores que trabalha mais de 40 aulas semanais, em diferentes redes de ensino, chega a quase 20 por cento. Merece destaque ainda o fato de que 14 por cento dos professores declararam trabalhar em outra atividade remunerada além da docência para complementar o salário, tais como pintura de residências, jardinagem, venda de pães, confecção e comércio de artesanato, tutoria em instituições de educação a distância, trabalho em empresas etc.

Aos professores também foi questionada a carga horária semanal destinada às atividades extraclasse, entendendo-se, para fins da pesquisa, aquelas relacionadas diretamente ao exercício da docência, como: preparo de aulas, elaboração e correção de atividades, provas e trabalhos, atendimento a alunos e pais de alunos, preenchimento de documentos ou formulários etc., excluindo-se as horas previstas no contrato para as Aulas de Trabalho Pedagógico Coletivo (ATPC), cumpridas na escola, e para as Aulas de Trabalho Pedagógico em Local de Livre Escolha (ATPL). Dessa forma, os professores quantificaram as horas trabalhadas, mas não remuneradas. A partir das respostas chegou-se aos dados da Tabela 3.

Tabela 3 - Carga horária de trabalho extraclasse declarada pelos professores

\begin{tabular}{|c|c|c|}
\hline Carga horária extraclasse & $\mathrm{N}^{0}$ de professores & $\%$ \\
\hline 0 horas & 5 & $1,08 \%$ \\
\hline 1 a 5 horas & 155 & $33,41 \%$ \\
\hline 6 a 10 horas & 170 & $36,64 \%$ \\
\hline 11 a 15 horas & 69 & $14,87 \%$ \\
\hline 16 a 20 horas & 14 & $3,02 \%$ \\
\hline 21 a 25 horas & 8 & $1,72 \%$ \\
\hline 26 a 30 horas & 6 & $1,29 \%$ \\
\hline mais que 30 horas & 24 & $5,17 \%$ \\
\hline Rasurado & 1 & $0,22 \%$ \\
\hline Em branco & 12 & $2,59 \%$ \\
\hline TOTAL & 464 & $100,00 \%$ \\
\hline
\end{tabular}

Fonte: Elaboração própria, com base em dados obtidos com o questionário da pesquisa. 
Esses dados evidenciaram a insuficiência do tempo de trabalho extraclasse previsto na jornada oficial desses professores. Se os respondentes não dedicassem nenhuma hora a mais do que as previstas em sua jornada (lembrando que a pergunta excluía da estimativa as horas de ATPC e ATPL), poderíamos interpretar que o número de horas legalmente destinadas ao trabalho extraclasse previsto na jornada era suficiente para dar conta da demanda de trabalho docente. No entanto, o percentual de professores que declarou não trabalhar nenhuma hora extraclasse, associado às respostas rasuradas ou em branco, totalizou 3,88 por cento. Todos os outros professores declararam destinar horas além das contratuais para a realização do trabalho extraclasse. A maior incidência de respostas ocorreu na faixa de 1-5 horas (33,41 por cento) e $6-10$ horas (36,64 por cento), com destaque para 5,17 por cento que declararam trabalhar mais de 30 horas semanais nesse tipo de atividade.

Para obtermos a média de horas extraclasse trabalhadas pelos professores, bem como o tempo total de trabalho (aulas + extraclasse), tomamos o valor do ponto médio de cada classe presente na Tabela 3 (3, 8, 13, 18, 23, 28 e 33). A partir desses valores, calculamos a média de horas extraclasse trabalhadas por todos os professores em 9,23 horas/semana (com desvio padrão de 1,63 e coeficiente de variação de 18 por cento). Somamos, então, para cada questionário, o ponto médio da classe referente às horas extraclasse declaradas pelo professor, com a quantidade de aulas que os professores informaram (considerando uma hora por aula), totalizando, para cada professor, a quantidade total de horas trabalhadas (remuneradas ou não) na docência. Não foram contabilizadas, para esse total de horas, aquelas apontadas para outras atividades não docentes. 0 tempo total de trabalho é, em média, 40,79 horas/semana (com desvio padrão de 14,77 e coeficiente de variação de 36 por cento). A mediana é de 39 horas. Esses dados foram calculados excluindo-se os questionários que tiveram rasura/branco em qualquer uma das perguntas que envolvessem o total de aulas e a carga horária extraclasse. A amostra tornou-se, então, de 441 professores, cujos dados estão apresentados na Tabela 4.

Tabela 4 - Carga horária total de trabalho

\begin{tabular}{|c|c|c|}
\hline $\mathrm{N}^{0}$ de horas semanais & $\mathrm{N}^{0}$ de professores & $\%$ \\
\hline $1-10$ & 2 & $0,45 \%$ \\
\hline $10-120$ & 26 & $5,90 \%$ \\
\hline $20-130$ & 73 & $16,55 \%$ \\
\hline $30-40$ & 158 & $35,83 \%$ \\
\hline $40-150$ & 77 & $17,46 \%$ \\
\hline $50-60$ & 58 & $13,15 \%$ \\
\hline $60-170$ & 32 & $7,26 \%$ \\
\hline $70-180$ & 11 & $2,49 \%$ \\
\hline $80-190$ & 3 & $0,68 \%$ \\
\hline $90-100$ & 1 & $0,23 \%$ \\
\hline TOTAL & 441 & $100,00 \%$ \\
\hline
\end{tabular}

Fonte: Elaboração própria, com base em dados obtidos com o questionário da pesquisa.

\footnotetext{
7- Lembrando que as perguntas referentes à quantidade de aulas ministradas solicitavam um número absoluto para cada uma delas, enquanto a pergunta referente à quantidade de horas de trabalho extraclasse solicitava a escolha de uma categoria. Por esse motivo, para fazer a soma dos dois valores aqui apresentados, utilizamos o ponto médio de cada classe. Quanto à elaboração do questionário, entendemos que os professores teriam dificuldade para quantificar de forma exata as horas de trabalho extraclasse (algo que confirmamos, como veremos mais adiante, nas entrevistas). Por isso, coletamos esse dado a partir de classes e, aqui, operamos com os pontos médios.
} 
Podemos observar que 35,83 por cento dos professores apresentaram uma carga horária total de trabalho entre 31 e 40 horas semanais; 16,55 por cento entre 21 e 30 horas semanais e 17,46 por cento entre 40 e 50 horas semanais. Destacamos os 6,35 por cento de professores que trabalhavam até 20 horas semanais e a porcentagem total de 41,27 por cento de professores com mais de 40 horas semanais, além dos 10,66 por cento que trabalhavam mais do que 60 horas na semana.

Esses dados devem ser compreendidos a partir da especificidade da docência como atividade extensa e intensa, que exige muito do professor no aspecto intelectual, físico e, principalmente, emocional. Além disso, é necessário considerar que para compor a jornada de trabalho, os professores dos anos finais do ensino fundamental e do ensino médio, assumem aulas em muitas salas e/ou turmas. Para compor uma jornada integral, com 32 horas semanais de trabalho em sala de aula, o professor de disciplinas com duas aulas semanais por turma deverá assumir aulas em dezesseis turmas diferentes e, em muitas situações, quando não é possível completar a jornada em uma mesma unidade escolar, em diferentes lugares. Se considerada uma média de 35 alunos por turma, haverá 560 alunos por professor, o que significa 560 sujeitos com os quais deverá interagir, 560 provas para corrigir etc.

Para compreender melhor as implicações dessa jornada de trabalho, realizou-se, em etapa posterior da pesquisa, entrevistas com treze professores das escolas que haviam participado da primeira fase da investigação. As entrevistas foram fundamentais para aproximação do universo profissional dos professores, reconhecendo as implicações das condições de trabalho, especialmente da jornada, na realização das atividades laborais.

O Quadro 2 apresenta uma breve caracterização dos entrevistados identificados com nomes fictícios.

Quadro 2 - Caracterização dos sujeitos da pesquisa

\begin{tabular}{|c|c|c|c|c|c|c|c|}
\hline Nome & $\begin{array}{l}\text { Situação } \\
\text { funcional }\end{array}$ & $\begin{array}{l}\text { Tempo de } \\
\text { experiência } \\
\text { docente }\end{array}$ & $\begin{array}{l}\mathrm{N}^{0} \text { de } \\
\text { cargos } \\
\text { na rede }\end{array}$ & $\begin{array}{c}\mathrm{N}^{0} \text { de horas-aula } \\
\text { semanais trabalhadas } \\
\text { na rede }\end{array}$ & $\begin{array}{l}\text { Tempo destinado } \\
\text { às atividades } \\
\text { extraclasse }\end{array}$ & $\begin{array}{l}\text { Trabalha em } \\
\text { outras redes? } \\
\text { Quantas horas? }\end{array}$ & $\begin{array}{c}\text { Exerce outra função } \\
\text { remunerada além da } \\
\text { docência? }\end{array}$ \\
\hline Pedro & $\begin{array}{c}\text { Temporário } \\
\text { (cat. 0) }\end{array}$ & 15 anos & - & 31 & $4 \mathrm{~h}$ & 0 & Não \\
\hline Camila & $\begin{array}{c}\text { Temporária } \\
\text { (cat. 0) }\end{array}$ & 2 anos & - & 33 & $14 \mathrm{~h}$ & 0 & Não \\
\hline Luís & $\begin{array}{c}\text { Temporário } \\
\text { (cat. 0) }\end{array}$ & 2 anos & - & 18 & $12 \mathrm{~h}$ & 0 & Não \\
\hline Francisco & Efetivo & 20 anos & 1 & 38 & Não quantificou & 0 & $\operatorname{Sim}$ \\
\hline Fátima & Efetivo & 7 anos & 1 & 40 & $5 \mathrm{~h}$ & 0 & Sim \\
\hline Cláudia & Efetivo & 33 anos & 2 & 42 & $8 \mathrm{~h}$ & 21 & Não \\
\hline Carlos & Efetivo & 15 anos & 2 & 56 & $6 \mathrm{~h}$ & 0 & Sim \\
\hline Lúcia & Efetiva & 25 anos & 1 & 25 & $2 \mathrm{~h}$ & 26 & Não \\
\hline Joana & Efetiva & 30 anos & 1 & 40 & $15 \mathrm{~h}$ & 11 & Não \\
\hline Ester & Efetiva & 25 anos & 2 & 65 & $2 \mathrm{~h}$ & 0 & Não \\
\hline Ana & Efetiva & 38 anos & 1 & 37 & Não quantificou & 0 & Sim \\
\hline Glória & Efetiva & 7 anos & 1 & 38 & $15 \mathrm{~h}$ & 0 & Não \\
\hline João & Efetivo & 5 anos & 1 & 38 & $4 \mathrm{~h}$ & 0 & $\operatorname{Sim}$ \\
\hline
\end{tabular}

Fonte: Elaboração própria com base nas entrevistas realizadas na pesquisa. 
Os resultados das análises das entrevistas foram agrupados em três temas-eixo de análise que propiciaram a compreensão de elementos importantes sobre a constituição da jornada de trabalho docente na rede: dedicação ao trabalho e trabalho extraclasse; extensão da jornada de trabalho e sua relação com os salários; aumento das demandas de trabalho e desvalorização do trabalho docente.

\section{Dedicação ao trabalho e trabalho extraclasse}

A partir dos enunciados dos professores, identificamos que o tempo de trabalho é, de fato, muito maior do que o tempo de ensino, corroborando estudos realizados por Souza (2008). Todos os entrevistados relataram usar mais tempo que o previsto em sua jornada de trabalho para realizar as tarefas extraclasse: preparar aulas, provas e atividades; corrigir provas e atividades; pesquisar e estudar temas a serem abordados em aula; preencher diários de classe, fichas, formulários etc. Todas essas atividades são intrínsecas e essenciais para a estruturação e organização didática da aula, importante condição para a aprendizagem dos estudantes. 0 trabalho em sala de aula entrelaça-se com a preparação prévia do professor e com as atividades posteriores de avaliação e retorno aos alunos. Assim, o tempo de ensino integra o tempo de trabalho que, por sua vez, é difícil de ser quantificado, já que não é marcado exclusivamente pelo tempo marcado no relógio ou pelo toque do sinal que indica o início e o término da atividade.

Dois dos entrevistados, inclusive, nem mensuraram o número de horas que destinavam ao trabalho extraclasse. Ana, ao tentar quantificar, desiste, dizendo que a docência é profissão de tempo integral:

Preparar aula, eu preparo $24 \mathrm{~h}$ por dia, porque eu acordo de madrugada e penso em aula, eu vou pro mercado eu estou pensando no aluno que está com dificuldade... Fora o tempo que você está em casa e fala "deixa eu fazer uma pesquisa”, aí você pesquisa, lê [...], aí você está lá arrumando cozinha e você fala "ai caramba, mas aquele aluno daria para eu aplicar isso", entendeu? Então, assim, o professor ele pensa na aula $24 \mathrm{~h}$ por dia. É profissão de tempo integral. (Ana).

A fala de Ana reforça pesquisas de Fernández Enguita (1991), Duarte (2008) e Souza (2008): a docência extrapola o tempo da sala de aula e se torna profissão de tempo integral, evidenciando que o trabalho extraclasse se mistura ao tempo privado, ao tempo não normativo, realizado em casa ou em espaços e tempos diversos à escola.

Nesse sentido, os professores foram unânimes ao afirmar que levam trabalho para casa e dois deles trouxeram indicativos de que o processo de ensino e aprendizagem é constituído de múltiplas atividades, sobretudo se o professor é comprometido com a qualidade do atendimento que dá ao aluno:

[...] se eu gastar 3 ou 4 minutos da minha aula preenchendo cada diário, claro, seria ótimo pra mim, mas eu consigo atender dois alunos nesse tempo e tirar dúvida. E eles não me deixam fazer mesmo, porque eles vêm toda hora tirar dúvida. Então é um tempo que você quer ajudar o aluno, naquele pouquinho de tempo que você tem pra ficar com ele. (Glória). 
[...] eu não consigo fazer isso, não só por uma questão moral mesmo, já que esse não é o trabalho que tem que ser feito em sala de aula, né? Mas [...] da forma como eu dou aula, que é uma aula mais dinâmica, mais falada, conversada com os alunos, com bastante debate, eu não consigo fazer isso. Até isso tem a ver um pouco com o diário, né? Assim, é uma coisa que, às vezes, aparece: “nossa, por que você não faz o diário 5 minutinhos na sala de aula?”. Eu não fico 5 minutos parado na sala, é muito raro isso. Então estou o tempo todo falando com eles, andando pela sala, ajudando na atividade. Nesse ponto eu percebo que a gente trabalha mais. (João).

Os enunciados evidenciaram que quanto mais comprometidos com o trabalho e com as escolhas didáticas, dedicando atenção aos estudantes e ajudando-os nas atividades, mais trabalho os professores levarão para fora da escola. Glória e João compreendem que o preenchimento dos diários, por exemplo, não deve ser feito em sala de aula, priorizando a interação com os alunos. Como consequência, levam o material para completar em casa, em um tempo não remunerado suficientemente para todas as atividades que devem realizar.

A professora Glória, quando questionada a respeito do número de horas que gasta com o trabalho extraclasse, ressaltou:

\begin{abstract}
No meu caso específico, realmente é muito porque eu... apesar da escola ainda ser arcaica, eu tento ser um pouquinho moderna, então fora daqui eu tenho que trabalhar o grupo do Facebook em que tem todos os meus alunos, que recebem todos os meus recados, tem sugestões de videoaulas, lista de exercícios e coisas desse tipo. Além disso, eu tenho um website no qual eu vou compartilhar as listas de exercícios, colocar os gabaritos das listas de exercícios e sugestões de recuperação em videoaula ou videoaulas que vão entrar no assunto que quero trabalhar na outra semana, então eu coloco a videoaula hoje e sugiro que assistam, se assistirem e trouxerem anotações tem até uns pontinhos extras por isso [...]. E, além disso, eu tenho um canal no YouTube onde eu tenho aulas minhas que eu gravo com mesa digitalizadora, coisas desse tipo. Eu especificamente gasto mais horas do que eu deveria com tudo isso. Além disso, tem as correções de provas, preparar todas as provas e aulas. (Glória).
\end{abstract}

A fala de Glória é representativa do tempo de trabalho que se estende muito além do tempo de ensino. A sua aula é preparada antes do encontro com os alunos e se estende com a seleção de exercícios, vídeos, videoaulas etc. para aprofundamento do conteúdo. Recorrendo a dispositivos tecnológicos, a professora sustenta a interação com os alunos por meio do Facebook e das aulas no canal do Youtube, o que demanda muitas horas extraclasse. A educação mais inclusiva e o uso de tecnologias que possam favorecer o processo de ensino exigem maior tempo de dedicação dos professores. Se o trabalho extraclasse já era marca da rotina do professor, ele está muito mais presente em tempos atuais, quando apenas o giz e a lousa não são suficientes para o atendimento a um público mais heterogêneo.

\title{
Extensão da jornada de trabalho e sua relação com os salários
}

As jornadas de trabalho docente estão diretamente relacionadas aos salários recebidos pelos professores, pois eles são, normalmente, calculados em função do número 
de horas trabalhadas pelos professores. Vários pesquisadores têm sinalizado que os salários dos professores brasileiros são considerados baixos, sobretudo em relação às profissões para as quais se exige igual nível de formação (ALVES; PINTO, 2011; BARBOSA, 2011; JACOMINI; ALVES; CAMARGO, 2016). Os baixos salários levam os professores a ampliar as jornadas de trabalho para ampliar suas remunerações (BARBOSA, 2011).

Conforme anteriormente apontado, os professores entrevistados não foram escolhidos em razão de sua jornada de trabalho. Mesmo assim, a caracterização dos sujeitos sistematizada no Quadro 2 apontou que nove dos treze professores (todos eles efetivos) tinham jornadas de trabalho com mais de 40 horas-aula semanais compostas na própria rede paulista, com dois cargos públicos, ou em outras redes públicas e privadas. Nesse grupo, havia ainda professores realizando outras atividades remuneradas, como pintura de residências, jardinagem, venda de pães, artesanato, tutoria em instituições de educação a distância e trabalho em empresas. Dentre os quatro professores restantes, uma professora afırmou que, apesar de precisar de mais aulas, naquele momento não era possível, pois ela cursava o mestrado e precisava de tempo para concluir o curso; os outros três docentes eram contratados temporariamente (categoria $0^{8}$ ) e, ainda que quisessem, não poderiam ter jornada maior que $40 \mathrm{~h} /$ semana na rede, aliás, a forma de contratação desses professores é por carga horária e não jornada, condição exclusiva dos titulares de cargo aprovados em concursos públicos.

Ainda que decorrente de uma seleção aleatória e dependente de participação voluntária, os sujeitos da pesquisa tinham jornadas de trabalho bastante extensas, sendo unânimes ao afirmar que o aumento das horas de trabalho (de suas próprias jornadas de ou de seus colegas) decorria da necessidade de complementar os baixos salários.

0 enunciado de Luís, professor temporário da disciplina de sociologia, é representativo desse grupo:

É bem ruim. E não faz menor sentido todo esse discurso de melhorar a educação e continuar pagando isso [...]. Eu acho que toda vez que o governo fala que vai melhorar a educação, eles tentam fazer desviando dessa questão, né? Mas não tem como fugir porque se você aumentar, a pessoa vai pegar uma carga menor de aulas, ela vai ter menos salas, vai conseguir se dedicar mais aos alunos, conhecer mais os alunos, elaborar melhor essas aulas. Porque eu acho que quanto menor o salário, mais aulas as pessoas pegam e menos tempo elas têm livre para se dedicar ao que tem que fazer, uma aula, corrigir trabalho... Aí a aula perde qualidade cada vez mais. (Luís).

0 excerto de Luís evidencia o questionamento sobre a pertinência da busca pela qualidade da educação desvinculada dos salários docentes e da jornada de trabalho. Os baixos salários comprometem a qualidade das atividades docentes, pois os professores têm menos tempo para se dedicar às atividades extraclasse, que são fundamentais e estruturantes para a organização do processo pedagógico.

\footnotetext{
8- A classe do magistério é formada por professores efetivos (admitidos por concurso público) e não efetivos, que, por sua vez, podem ser estáveis (por força de lei), temporários (contratados por período determinado para preenchimento das vagas ociosas, como é o caso dos professores da Categoria 0), ou ainda eventuais (que substituem outros docentes por período inferior a 15 dias).
} 
Além de relacionar as jornadas aos salários, os professores ainda mencionaram as consequências da ampliação da carga horária que, segundo Carlos, prejudica a formação e a qualidade de vida e de trabalho desses profissionais:

De fato, o salário não atende à necessidade de um professor, principalmente do professor que quer, que gosta de dar aula, que sente prazer em dar aula. Ele precisa ter um salário que possa garantir uma qualidade de vida e garantir a qualidade de vida do professor significa garantir a qualidade da educação. 0 professor que ganha um salário digno, por exemplo, tem uma formação melhor, tem tempo para o lazer... então isso acaba mudando totalmente a postura do professor. (Carlos).

Nesse sentido, Gouveia et al. (2006, p. 262) já destacavam que "a extensão da jornada de trabalho também é um fator importante para a efetivação de um ensino de qualidade, posto que cargas de trabalho excessivas, além da questão da saúde, implicam em dificuldades para a própria atualização profissional”.

Já a referência feita por Lúcia aproximou-se dos resultados de pesquisas sobre atratividade da docência apresentados por Gatti et al. (2010):

Hoje em dia, os eventuais estão fugindo e já ocorreu da secretaria ligar para trinta, trinta eventuais! E ninguém quis! [...]. Os três anos que eu fiquei na outra escola os alunos não tinham aula de geografia, não tinha professor e ninguém queria essas aulas. Porque se um professor efetivo já não tem lá aquele salário, um eventual muito menos. Eles preferem vender roupa, vender bolinho, vender qualquer outra coisa [...]. (Lúcia).

Como destacado pela professora Lúcia, “[...] eles [os eventuais] preferem vender roupa, vender bolinho, vender qualquer coisa [...]”, indicando a relação entre baixos salários e atratividade docente. A fala da professora Ana, em seguida, ilustra um cenário preocupante no qual os professores são levados a desempenhar outras atividades para complementar os salários. No caso específico dessa professora, ela fazia pintura de residências nos finais de semana, feriados e férias para manter os filhos estudando:

Eu acho ofensivo! Pelo trabalho que eu desempenho e que eu vejo colegas meus desempenhando, eu acho ofensivo. Não tem outra forma de eu me referir ao meu salário [...]. Porque eu acho assim, todo ser humano que trabalha um pouco mais e não ganha o suficiente pra sustentar os filhos é vergonhoso. Quando a minha filha me pede um livro de direito e eu tenho que pintar um apartamento pra comprar o livro, nas minhas férias, é muito triste, é vergonhoso, né? [Lágrimas]. (Ana).

A professora Ana demonstra sentir-se desrespeitada por exercer uma atividade importante como a docência - "pelo trabalho que eu desenvolvo e que eu vejo meus colegas desempenhando" - e ter que complementar sua renda fazendo pinturas para atender às necessidades dos filhos. Ela sinaliza para a importância social da docência que não é correspondida pelos salários. 


\section{Aumento das demandas de trabalho e desvalorização do trabalho docente}

Os professores entrevistados ainda relataram que as demandas de trabalho aumentaram muito nos últimos anos juntamente com a incisiva cobrança por resultados, corroborando dados da pesquisa realizada por Cunha, Barbosa e Fernandes (2015). Um dos entrevistados externalizou a sensação de sempre estar em débito diante das exigências que não param de chegar às escolas:

Parece que está sempre devendo, que não está dando o melhor dele, que ele não consegue chegar aonde ele queria chegar, que o trabalho não está completo. A sensação de não ter um trabalho completo é muito frustrante pra um profissional, seja ele de qualquer área. (Carlos).

Para além das demandas que vão desde questões pedagógicas - utilizar novas metodologias, adaptar-se à heterogeneidade dos estudantes, prepará-los para as avaliações externas - até questões mais amplas e diversas presentes numa escola mais aberta e inclusiva que pressupõe participação na gestão, ampliação do atendimento aos pais etc., os entrevistados também relataram redução das condições básicas para a realização de um trabalho de qualidade:

[...] hoje não tem giz branco pra gente trabalhar e a culpa é da diretora? Não, porque ela sabe que quando não tem ela tira do bolso. Não tem papel higiênico, às vezes tem que trazer de casa. Como é que pode você não ter papel para imprimir prova para molecada? Então isso daí vai deixando a gente... não tem papel, não tem tinta, não tem para o básico. Para fazer diferença, fazer o que eles querem para aumentar o índice, uma aula diferenciada... Mas você não tem estrutura para isso, não tem um laboratório. Eu tenho que ficar levando caixas e caixas para lá e para cá... não tem problema, mas uma aula que eu daria em 10 minutos eu gasto meia hora, porque até eu montar e desmontar, levar. Então é uma falta de estrutura que também ajuda a frustrar e a gente fica louco, porque a cobrança vem. (Francisco).

Francisco reclama da falta de materiais elementares para o trabalho - giz, papel, tinta, laboratório - e a exigência de melhoria nos índices de aproveitamento escolar. 0 professor argumenta que "para fazer diferença" na formação dos alunos e dar "uma aula diferenciada” é necessário estrutura mínima para a realização do trabalho. Ele lamenta: “a cobrança vem...". A cobrança por resultados, citada explicitamente por três professores nas entrevistas, é parte da política de responsabilização que caracteriza a Nova Gestão Pública e tem sido objeto de pesquisadores no estado de São Paulo (RODRIGUES, 2018), constituindo-se num elemento de ampliação das demandas cotidianas.

Alguns professores reconheceram que a expansão da escola pública trouxe para dentro dela uma heterogeneidade que acarretou maiores demandas para o professor, as quais, muitas vezes, ele não consegue dar conta, sobretudo em função das condições que tem para desempenhar o trabalho, o que gera desgaste e frustração: 
Porque o professor hoje vê a questão dos alunos como uma necessidade mesmo de uma atenção maior, principalmente o aluno da escola pública, e ele não consegue dar o mínimo que ele queria e isso é muito frustrante pro professor [...]. Então ele vê um aluno lá, que não está legal naquele dia, um aluno que de repente está diferente, está agressivo, ele não consegue nem fazer um diagnóstico, nem uma abordagem, porque a condição da sala e a condição também da superlotação, que pesa muito pro professor, então é a questão da quantidade, da sobrecarga de trabalho. 0 professor tem trabalhado de manhã, de tarde e à noite. Ele chega num momento que começa a não dar conta de tudo daquilo que está desenvolvendo, e é frustrante. A autoestima do professor está baixa, como profissional que ele é. Hoje mesmo estava ouvindo a nossa coordenadora falando: "Olha, eu terminei toda a questão burocrática, que satisfação". Isso é interessante pro trabalhador, quando ele reconhece que deu conta, que está tudo realizado perfeitamente, isso traz uma autoestima, uma valorização, e o que eu percebo é que o professor não tem isso [...]. (Carlos).

Os professores demonstraram ser positivas algumas mudanças no cotidiano escolar, tais como a democratização do acesso que ampliou o número de alunos por turmas e favoreceu a heterogeneidade da composição dessas turmas, mas indicaram que num cenário de precárias condições de trabalho, esse fato acarretou novas demandas para o docente. Para Oliveira (2002), as reformas educacionais implantadas a partir dos anos 1990 no Brasil introduziram mudanças na organização escolar que alteraram consideravelmente o trabalho docente. 0 excerto da fala da professora Glória parece fazer referência a isso:

Eu tenho a impressão que a escola está cada vez exigindo mais de mim e... o fato é que veio mudanças que eu vi que são positivas, de realmente você avaliar o aluno por habilidades, por competências, por todo esse processo, coisa que antigamente não se via. Você simplesmente chegava e dava a aula, se não entendeu, tudo bem [...]. Hoje em dia, se vai preparar uma prova [...] você não pode dar uma questão não contextualizada, então você tem que pesquisar as questões que você vai dar [...]. Você trabalha toda uma estrutura, faz uma ligação com o mundo real, você tem que tentar... Aquela questão vai desenvolver qual habilidade do aluno? [...]. Então, você tem uma exigência maior nesse sentido, do próprio aluno de tentar atender a necessidade do aluno individualmente, coisa que você não pensava antigamente, e acho que esse processo demandou mais carga pra gente e a gente percebe que tem muita coisa pra fazer. (Glória).

Apesar do aumento das demandas de trabalho e das cobranças, a professora Glória ilustra a sensação de desvalorização que impera entre os professores:

Se as pessoas não começarem a perceber e a valorizar a escola, a função do professor e tudo que vem junto com isso, não tem saída. Fora a questão de "Ah, mas você não pode ficar desmotivada porque seu salário é baixo". Eu posso sim, eu posso sim! Porque pra vir trabalhar eu tenho que abrir a minha geladeira, eu tenho que abrir e ver que eu não tenho mais nada lá dentro e ainda não chegou o final do mês. E falar que eu não posso ficar desmotivada de sair da minha casa nessa situação é ridículo! (Glória). 
0 excerto supracitado pode ser interpretado a partir dos estudos portugueses de Correia e Matos (2001) que trouxeram à tona a perda do poder dos professores que, segundo os autores, se assentava no passado, em uma delegação cognitiva muito evidente: os professores eram depositários do saber científico e tinham a sensação de ensinar algo aos estudantes, mesmo que isso não encontrasse evidências na prática de uma escola seletiva.

As mudanças no contexto escolar, caracterizadas neste artigo por um município, não foram acompanhadas por melhorias significativas nas condições de trabalho, especialmente na jornada de trabalho composta pelo tempo de ensino e tempo extraclasse. Tal fato acarretou desgaste e frustração por parte dos professores, o que altera o sentido e o significado do trabalho docente.

\section{Algumas considerações possíveis}

Ainda que seja difícil aferir e quantificar o número de horas efetivamente trabalhadas pelos professores, desafio enfrentado na pesquisa realizada, os resultados apontaram para elementos importantes na discussão da jornada de trabalho docente. Nesse sentido, identificamos que a constituição da jornada de trabalho na rede pública estadual paulista ultrapassa, em muito, o tempo da jornada de trabalho oficial que compõe o cargo. A maioria dos professores que participaram da primeira etapa da pesquisa, respondendo aos questionários, e a totalidade dos professores que participaram da segunda etapa, concedendo entrevistas, sinalizaram a necessidade de dedicar várias horas de trabalho semanal extraclasse, além das previstas, para a realização de atividades essenciais à ação em sala de aula.

Os dados sinalizaram a insuficiência da utilização única dos dados oficiais de jornada de trabalho docente - que consideram somente o tempo de ensino, ou mesmo o tempo total remunerado - tanto nas pesquisas sobre a temática como na formulação de políticas para o magistério, já que o número de horas efetivamente trabalhadas é superior ao número de horas que consta nos dados oficiais. A associação frequente que os sujeitos dessa pesquisa fizeram entre jornada e salário docente sinalizou que a ampliação das horas de trabalho é estratégia docente recorrente para equilibrar os ganhos salariais considerados baixos, o que demonstra desvalorização profissional, acarretando maior demanda de trabalho e até mesmo adoecimento.

Assim, a compreensão mais afinada da jornada de trabalho docente requer um olhar atento ao cotidiano das escolas, onde os profissionais trabalham muito, em jornadas extensas e intensas que extrapolam o tempo oficial e regulamentar de trabalho.

\section{Referências}

ALVES, Thiago; PINTO, José Marcelino de Rezende. Remuneração e características do trabalho docente no Brasil: um aporte. Cadernos de Pesquisa, São Paulo, v. 41, n. 143, p. 606-639, 2011.

ASSUNÇÃO, Ada Ávila. Condições de trabalho e saúde dos trabalhadores da saúde. In: MINAYO, Carlos; MACHADO, Jorge Mesquita Huet; PENA, Paulo Gilvane Lopes. Saúde do trabalhador na sociedade 
brasileira contemporânea. Rio de Janeiro: Fiocruz, 2011. p. 453-478.

BARBOSA, Andreza. Os salários dos professores brasileiros: implicações para o trabalho docente. Brasília, DF: Liber Livro, 2011.

BARBOSA, Andreza; CUNHA, Renata Cristina Oliveira Barrichelo; MARTINS, Verônica. Estado do conhecimento sobre jornada de trabalho docente no ensino fundamental e médio. Horizontes, Itatiba, v. 37, p. 1-27, 2019.

BRASIL. Conselho Nacional de Educação. Resolução n² 2, de 28 de maio de 2009. Diário Oficial da União, Brasília, DF, 29 maio 2009. Disponível em: https://www.jusbrasil.com.br/diarios/691083/pg-41-secao-1diario-oficial-da-uniao-dou-de-29-05-2009. Acesso em: 20 out. 2021.

BRASIL. Lei n 11.738, de 16 de julho de 2008. Diário Oficial da União, Brasília, DF, 16 jul. 2008. Disponível em: http://www.planalto.gov.br/ccivil_03/_ato2007-2010/2008/lei/l11738.htm. Acesso em: 20 out. 2021.

CORREIA, José Alberto; MATOS, Manuel Santos e. Solidões e solidariedades nos quotidianos dos professores. Porto: ASA, 2001.

CUNHA, Renata Cristina Oliveira Barrichelo; BARBOSA, Andreza; FERNANDES, Maria José da Silva. Implicações das avaliações externas para o trabalho docente coletivo. Estudos em Avaliação Educacional, São Paulo, v. 26, n. 62, p. 386-416, 2015.

DUARTE, Adriana Maria Cancella. 0 trabalho docente na educação básica: novas configurações e formulações teórico-conceituais. In: SEMINARIO DE LA RED DE ESTUDIOS SOBRE TRABAJO DOCENTE, 7., 2008, Buenos Aires. Anais [... . Buenos Aires: Red Estrado, 2008. 1 CD-ROM.

FARIA, Graciela Sanjutá Soares; RACHID, Alessandra. Jornada de trabalho dos professores da rede pública de ensino. FAE, Curitiba, v. 18, n. 2, p. 162-177, 2015.

FERNANDES, Maria José da Silva; BARBOSA, Andreza. 0 trabalho docente na rede pública do estado de São Paulo: apontamentos iniciais para a discussão da jornada de trabalho. Práxis Educacional, Vitória da Conquista, v. 10, n. 17, p. 117-142, 2014.

FERNÁNDEZ ENGUITA, Mariano. A ambiguidade da docência: entre o profissionalismo e a proletarização. Teoria \& Educação, Porto Alegre, n. 4, p. 41-61, 1991.

GATTI, Bernardete Angelina; BARRET0, Elba Siqueira de Sá (coord.). Professores do Brasil: impasses e desafios. Brasília, DF: Unesco, 2009.

GATTI, Bernardete A. et al. A atratividade da carreira docente no Brasil. In: FUNDAÇÃO VICTOR CIVITA. Estudos \& pesquisas educacionais. São Paulo: Fundação Victor Civita, 2010.

GOUVEIA, Andréa Barbosa et al. Condições de trabalho docente, ensino de qualidade e custo-aluno-ano. Revista Brasileira de Política e Administração da Educação, Brasília, DF, v. 22, n. 2, p. 253-276, 2006. 
IPM. Instituto Paulo Montenegro. Ser professor: uma pesquisa sobre o que pensa o docente das principais capitais brasileiras. In: FUNDAÇÃO VICTOR CIVITA. Estudos \& pesquisas educacionais. São Paulo: Fundação Victor Civita, 2010. v. p. 17-61.

JACOMINI, Márcia Aparecida; ALVES, Thiago; CAMARGO, Rubens Barbosa de. Remuneração docente: desafios para o monitoramento da valorização dos professores brasileiros no contexto da meta 17 do Plano Nacional de Educação. Arquivos Analíticos de Políticas Educativas, [s. I.], v. 24, n. 73, p. 1-32, 2016.

JACOMINI, Márcia Aparecida; GIL, Juca; CASTRO, Edimária Carvalho de. A Lei do Piso e a jornada: 0 trabalho docente nos estados. Retratos da Escola, Brasília, DF, v. 13, n. 25, p. 259-273, 2019.

JACOMINI, Márcia Aparecida; GIL, Juca; CASTRO, Edimária Carvalho de. Jornada de trabalho docente e 0 cumprimento da Lei do Piso nas capitais. Revista Brasileira de Política e Administração da Educação, Brasília, DF, v. 34, n. 2, p. 437-459, 2018.

OLIVEIRA, Dalila Andrade. Mudanças na organização e na gestão do trabalho na escola. In: OLIVEIRA, Dalila Andrade; ROSAR, Maria de Fátima Félix (org.). Política e gestão da educação. Belo Horizonte: Autêntica, 2002. p. 125-143.

OLIVEIRA, Dalila Andrade; ASSUNÇÃO, Ada Ávila. Condições de trabalho docente. In: OLIVEIRA, Dalila Andrade; DUARTE, Adriana Maria Cancella; VIEIRA, Lívia Fraga (org.). Dicionário: trabalho, profissão e condição docente. Belo Horizonte: UFMG, 2010. p. 1-4.

OLIVEIRA, Dalila Andrade; VIEIRA, Lívia Fraga. Condições de trabalho docente: uma análise a partir de dados de sete estados brasileiros. In: OLIVEIRA, Dalila Andrade; VIEIRA, Lívia Fraga (org.). Trabalho na educação básica: a condição docente em sete estados brasileiros. Belo Horizonte: Fino Traço, 2012. p. 153-190.

PAGANI, Gabriela. Quando os professores desistem: um estudo sobre exoneração docente na rede estadual de ensino de São Paulo. 2019. Dissertação (Mestrado em Educação Escolar) - Faculdade de Ciências e Letras, Universidade Estadual Paulista Júlio de Mesquita Filho, Araraquara, 2019.

RODRIGUES, Jean Douglas Zeferino. Gerencialismo e responsabilização: repercussões para o trabalho docente nas escolas estaduais de ensino médio de Campinas/SP. 2018. Tese (Doutorado em Educação) Faculdade de Educação, Universidade Estadual de Campinas, Campinas, 2018.

SÃO PAULO (Estado). Lei Complementar nº 836, de 30 de dezembro de 1997. São Paulo: Assembleia Legislativa do Estado de São Paulo, 1997. Disponível em: https://www.al.sp.gov.br/repositorio/legislacao/ lei.complementar/1997/lei.complementar-836-30.12.1997.html. Acesso em: 20 out. 2021.

SÃO PAULO (Estado). Resolução SE 8, de 19-1-2012. Diário Oficial, São Paulo, 20 jan. 2012. Disponível em: https://www.imprensaoficial.com.br/Certificacao/GatewayCertificaPDF.aspx?notarizacaolD=6cf6c7b9468c-4cb3-bec8-e40993fbc3a4. Acesso em: 20 out. 2021.

SINISCALCO, Maria Teresa. Perfil estatístico da profissão docente. São Paulo: Moderna, 2003. 
SOUZA, Aparecida Neri de. Condições de trabalho na carreira docente: comparação Brasil-França. In: SEMINARIO DE LA RED DE ESTUDIOS SOBRE TRABAJO DOCENTE, 7., 2008, Buenos Aires. Anais [...]. Buenos Aires: Red Estrado, 2008. 1 CD-ROM.

UNESCO. Recomendação relativa à condição dos professores. Paris: Unesco, 1966.

Recebido em: 30.03.2020

Revisado em: 17.08.2020

Aprovado em: 01.09.2020

Andreza Barbosa é professora do Programa de Pós-graduação em Educação da Universidade de Sorocaba, doutora em educação escolar pela Universidade Estadual Paulista (Unesp), mestre em educação pela Universidade de São Paulo (USP) e pedagoga pela Unesp.

Maria José da Silva Fernandes é geógrafa pela Universidade do Sagrado Coração, com especialização em ensino de geografia pela Pontifícia Universidade Católica de São Paulo (PUC-SP), mestrado e doutorado em educação escolar pela Universidade Estadual Paulista e professora do Programa de Pós-graduação em Educação Escolar (Unesp-Araraquara) e do Departamento de Educação (Unesp-Bauru).

Renata Cristina Oliveira Barrichelo Cunha é pedagoga pela Pontifícia Universidade Católica de São Paulo (PUC-SP) e doutora em educação pela Universidade Estadual de Campinas (Unicamp), pesquisadora colaboradora do Grupo de Estudos e Pesquisas em Educação Continuada (GEPEC/Unicamp) e assessora pedagógica do Instituto Pecege.

Thiago Borges de Aguiar é professor do Departamento de Metodologia de Ensino e Educação Comparada da Faculdade de Educação da Universidade de São Paulo (USP), pós-doutorando na Universidade Federal de São Paulo (Unifesp), doutor em educação (USP) e licenciado em pedagogia (USP) e em matemática pela Universidade Metodista de Piracicaba (Unimep). 